\title{
A NATUREZA E A CULTURA COMO ESTRATÉGIA DE DESENHO AMBIENTAL PARA ESTRELA DO SUL
}

\author{
Maria de Lourdes Pereira Fonseca, doutora em Urbanismo pela Universidade Politécnica de Cataluña, \\ professora adjunta da Universidad Federal do ABC - UFABC, loufonseca@yahoo.com \\ Giovanna Teixeira Damis Vital, mestre em Estruturas Ambientais Urbanas pela Universidade de São Paulo, \\ professora assistente da Universidade Federal de Uberlândia - UFU, gtdamis@yahoo.com
}

\begin{abstract}
Resumo
O artigo tem por objetivo apresentar os princípios utilizados para a elaboração do Plano Diretor Participativo de Estrela do Sul - MG. Essa cidade, de pequeno porte, está localizada na região do Triângulo Mineiro e se desenvolveu a partir de diversos núcleos de exploração de diamantes ao longo do Rio Bagagem, alcançando um grande destaque na região durante as últimas décadas do Século XIX. No entanto, devido à decadência da atividade mineradora, o município perdeu atratividade econômica e sua população reduziu drasticamente. O período áureo do garimpo deixou como herança um reconhecido conjunto de edificações históricas, mas também um ambiente fragmentado, espacial e socialmente, e com baixa qualidade urbana.
\end{abstract}

A estrutura espacial proposta para o município é organizada pelos ambientes natural hidrografia, cobertura vegetal e solo -, e construído - paisagem urbana e patimônio histórico-cultural -, tendo por princípios a conservação, a preservação e a recuperação de seu patrimônio cultural e a sustentabilidade, como forma promover a qualificação ambiental e a redução das desigualdades sócio-espaciais.

O trabalho destaca também o papel dos espaços livres, concebidos como infra-estrutura verde, e decisivos na estratégia de reverter a degradação ambiental e recuperar a paisagem para que a cidade possa abrigar um turismo histórico e rural, capaz de criar uma nova base econômica e garantir novas perspectivas de vida para seus habitantes.

Palavras-chave: Plano Diretor, Estrela do Sul, infra-estrutura verde, preservação ambiental, planejamento ambiental.

\section{THE NATURE AND THE CULTURE AS STRATEGY OF ENVIRONMENTAL DESIGN FOR ESTRELA DO SUL CITY}

\section{Abstract}


This paper has as objective to present the beginnings used for elaboration of Master Plan of Estrela do Sul city, state of Minas Gerais, Brazil. That city, small load, is located in Triângulo Mineiro area and it was developed starting from several nuclei of exploration of diamonds along the river Bagagem, reaching a great prominence in the area during the last decades of 19th Century. However, due to the exploring activity decadence, the city lost economic attractiveness and its population reduced drastically. The claim golden period left as inheritance a recognized group of historical constructions, but also a broken into fragments environment, space and socially, and with low urban quality.

The structure space proposal for municipal district is organized by the natural environment - hydrographic, vegetable covering and soil -, and by the built - urban landscape and historical-cultural heritage -, tends for beginnings the conservation, the preservation and the recovery of its cultural heritage and the sustainability, as form to promote the environmental qualification and the reduction of partner-space inequalities.

The work also highlights the paper of free spaces, conceived as a green and decisive infrastructure in the strategy to reverses the environmental degradation and to recover the landscape so that the city can shelter a historical and rural tourism, capable to create a new economic base and to guarantee new life perspectives for its inhabitants.

Key-word: Master plan, Estrela do Sul, green infrastructure, environmental preservation, environmental planning.

\section{Introdução}

Estrela do Sul é uma cidade histórica, situada na região do Triângulo Mineiro, implantada no vale do Rio Bagagem, que possui uma paisagem de significativa beleza, formada por Cerrados, Veredas e fragmentos da Floresta Estacional Semidecidual, relativamente preservados e que compõem, juntamente com o ambiente cultural, um cenário ambiental urbano diferenciado.

A cidade teve a sua fundação ligada à descoberta, em 1852, do famoso diamante "Estrela do Sul". O êxito da exploração de diamantes possibilitou um grande crescimento do povoado, que contabilizava, em 1861, aproximadamente, 30 mil habitantes e exercia uma grande influência política na região.

No entanto, esse período de crescimento e euforia começou a declinar a partir de 1870, em razão da descoberta das jazidas de diamantes da África do Sul, que fez o preço da pedra cair significativamente no mercado internacional. A partir de então, a população da cidade reduziu drasticamente, chegando a 8.524 habitantes, em 1970, e a 6.838 em $2001^{1}$. A atividade mineradora praticamente desapareceu e a sua economia passou a apoiar-se nas atividades agrícolas e pecuárias.

Os diversos núcleos de exploração do garimpo ao longo do Rio Bagagem deram origem a pequenos povoados que se desenvolveram de maneira quase autônoma e isolados, que foram, posteriormente, transformados em distritos: Sede (Estrela do Sul), Santa Rita, São

\footnotetext{
${ }^{1}$ Censo do IBGE 1970 e 2000.
} 
Félix de Estrela, Chapada de Minas e Dolearina. Apenas o Distrito Sede e Santa Rita, apresentam, apesar de uma descontinuidade de seu tecido urbano, uma relativa proximidade.

O município conta com significativo patrimônio histórico: oitente e seis (86) bens imóveis com tombamentos municipais, urbanos e rurais, os quais incluem, além de edifícios residenciais e comerciais, sedes de fazendas, túmulos e monumentos. A grande parte desse patrimônio arquitetônico encontra-se no distrito Sede e de Santa Rita, os núcleos de fundação da cidade.

A presença de imóveis históricos, associados às manifestações sócio-culturais, conferiram ao município o reconhecimento pelo Ministério do Turismo como cidade histórica do Triângulo Mineiro. Devido a isto, foi contemplada, em 2006, pelo programa de incentivos do Governo Federal para elaboração de planos diretores.

O Plano Diretor Participativo para Estrela do Sul foi desenvolvido pela Universidade Federal de Uberlândia - UFU, em parceria com a Prefeitura Municipal de Estrela do Sul e com o apoio do Conselho Nacional de Pesquisa - CNPq. A sua elaboração contou com a participação de professores e alunos da Faculdade de Arquitetura e Urbanismo, do Instituto de Geografia, do Instituto de Biologia, da Faculdade de Engenharia Civil e do Instituto de Economia da UFU e também de técnicos da prefeitura do referido município.

A partir da articulação das dimensões ambiental, físico-territorial, econômico-social e cultural buscou-se a hierarquização das necessidades e valorização das potencialidades do município, a fim de oferecer novas possibilidades econômicas e sociais. Buscou-se, dessa maneira, promover a sustentabilidade ambiental e o desenvolvimento local, além de potencializar os recursos culturais e ambientais e fomentar o turismo regional e a inclusão social.

Para o desenvolvimento dos trabalhos, seguindo-se as recomendações do Ministério das Cidades (BRASIL, 2004), foram definidas quatro etapas de trabalho: leituras técnica e comunitária; formulação e pactuação de propostas; definição dos instrumentos; sistema de gestão e planejamento municipal. A realização da leitura técnica foi realizada a partir da aplicação do modelo de avaliação ambiental denominado GEO Cidades (SÃO PAULO, 2004), e as leituras comunitárias foram feitas no formato de oficinas realizadas em cada distrito, separadamente, com a participação da população utilizando a metodologia de painéis. Os resultados estão compilados em duas partes: o Panorama do Meio Ambiente Urbano e Rural, que contém o levantamento e análise de dados técnicos e comunitários, e a indicação das diretrizes gerais para a elaboração das propostas do plano; o Plano Diretor do município, que traz abordagem teórico-conceitual do Planejamento Ambiental, metodologia de criação de cenários futuros e diretrizes.

\section{Patrimônio e Ambiente como princípio de sustentabilidade}

Um dos principais desafios a ser enfrentado pelo Município de Estrela do Sul é a perda de sua base econômica, problema vivido desde as últimas décadas do Século XIX, com o declínio da exploração mineradora. Ao longo do século XX, a cidade não conseguiu atrair indústrias, ficando à margem do desenvolvimento da região do Triângulo Mineiro, na qual se insere. Tendo como base econômica a agricultura e a pecuária, a cidade perdeu importância na rede regional de cidades, ficando, assim como muitas outras, ofuscadas e 
dependentes da dinâmica e da concentração econômica de Uberlândia e Uberaba, que se tornaram os pólos de crescimento da região.

Os processos de mudanças da economia, conhecidos como globalização, ocorridos a partir do final da década de 1970, definiram, no entanto, novas formas de articulação entre as diferentes cidades, permitindo a redefinição do papel de cada uma na rede global. A globalização, ao mesmo tempo que cria uma nova hierarquia de cidades, a escala mundial, abre também possibilidades para que as cidades se relacionem diretamente umas com as outras, independente de sua localização geográfica.

O aumento da mobilidade de pessoas, de informações, de mercadorias e de capitais abre também novas perspectivas econômicas, com o aumento da importância do setor de prestação de serviços e, especialmente, do turismo. Diante dessas circunstâncias, os planos e projetos estratégicos têm sido adotados como elementos capazes de posicionar favoravelmente a cidade na rede global e de adaptá-las às novas exigências da produção e reprodução do capital. O planejamento urbano passou a ser visto não apenas como elemento de ordenamento e controle do crescimento, mas como elemento fundamental da política econômica da cidade, fomentador do crescimento econômico local e capaz criar vantagens competitivas.

Dessa forma, paradoxalmente, a globalização, ao tornar relativa a importância das localizações, põe em relevo justamente as diferenças entre os lugares. Busca-se, então, através da exploração das potencialidades de cada cidade, uma posição de destaque e diferenciação das demais. A imagem e qualidade urbana passam a ser elemento estratégico na competição urbana e a atenção se volta para áreas já ocupadas ou intersticiais, vazias ou degradadas, requalificando e/ou adensando os seus usos, como forma de corrigir os desequilíbrios territoriais e sociais e valorizar os seus atributos ambientais.

Nesse contexto, as áreas históricas, assim como os monumentos, são vistos como estratégicos na formação e exploração da imagem urbana e de sua diferenciação, como lugar especial e propício ao abrigo de novos tipos de comércio e serviços dirigidos, especialmente, aos turistas.

Choay (2006) e Arantes (2000) alertam, no entanto, para o risco de mercantilização do patrimônio cultural, e da própria cidade, convertendo-os em produto de consumo cultural. Com vistas a uma exploração econômica de seu status histórico e patrimonial, os monumentos e os centros e bairros antigos são transformandos em produtos de consumo cultural e de uso para fins mediáticos. E, muitas vezes, são "tratados" e "arrumados" para agradar ao turista e facilitar o seu uso, transformados em cenários para a animação cultural, como estratégia de criação de um lugar na cidade destinado à evasão e ao consumo. Isso, associado à gentrificação social e de usos, pode levar à perda da autenticidade e à banalização do ambiente urbano.

Dessa maneira, um grande desafio que se coloca é a integração dos conjuntos históricos à vida coletiva contemporânea e, ao mesmo tempo, manter de seu particularismo e a sua capacidade de servir como referencial da História através do efeito de distância e de afastamento, a partir do qual se pode estabelecer uma leitura crítica da cidade.

Para combater essas tendências desagregadoras e descaracterizadoras, Choay (2006) propõe a "conservação estratégica" do patrimônio urbano antigo, que prevê desde a 
exposição controlada e normatizada dos monumentos a uma destinação de atividades compatíveis com a morfologia e as dimensões das malhas antigas, com a manutenção e a proteção de seus usos para os seus habitantes, garantindo um uso cotidiano e equilibrado. Assim sendo, os elementos novos devem respeitar a articulação e as regras morfológicas desses tecidos.

Da mesma forma, o patrimônio ambiental é também estratégico na formulação da nova base econômica das cidades e, portanto, na busca de um posicionamento favorável na rede urbana e deve ser abordado a partir dos conceitos do Planejamento Ambiental. $O$ Planejamento Ambiental tem como princípio "todo esforço da civilização na direção de preservar e conservar os recursos ambientais de um território, com vistas à sua própria sobrevivência" (FRANCO, 2000:34). Assim sendo, concebe a preservação do patrimônio ambiental e cultural como parte da preservação da própria biodiversidade, partindo-se do ambiente construído como o hábitat humano, como manifestação cultural, que, se destruída, não se reconstrói.

O princípio de sustentabilidade surge, então, no contexto da globalização apontando novos rumos para o desenvolvimento econômico, questionando a racionalidade e os paradigmas teóricos que fomentaram e legitimaram o crescimento econômico com base na negação da natureza (LEFF, 2001), o que terminou por desencadear a crise ambiental mundial. Nesta perspectiva, a sustentabilidade ecológica é o princípio de uma nova ordem econômica e, portanto, territorial, necessária a um crescimento duradouro e como condição para a sobrevivência humana e existência da vida, baseados nas potencialidades ecossistêmicas e no manejo prudente dos recursos naturais.

Assim, "O ambiente emerge como um saber reintegrador da diversidade, de novos valores éticos e estéticos e dos potenciais sinergéticos gerados pela articulação de processos ecológicos, tecnológicos e culturais" (LEFF, 2001, p. 17). Inicia, com isto, um processo de elaboração de novos padrões de produção e de estilo de vida baseados nas potencialidades ecológicas locais de cada região valorizando a diversidade étnica e na participação da população no processo de gestão dos recursos. Para Leff (2001), a sustentabilidade vem ecologizar a economia eliminando a contradição moderna entre economia e ecologia, por meio de um projeto que visa erradicar a pobreza, satisfazendo as necessidades básicas e melhorando a qualidade de vida da população.

No Plano Diretor de Estrela do Sul, assume-se, portanto, a questão ambiental atrelada aos princípios de conservação urbana, pois esta se estabelece a partir da necessidade de conservar, preservar e recuperar o meio ambiente garantindo a existência da vida.

\section{Estrela do Sul: estagnação econômica, fragmentação urbana e degradação ambiental}

Os problemas que afetam o município de Estrela do Sul, não diferem muito da realidade dos pequenos municípios do país. Apesar de ter a economia baseada nas atividades de agricultura e pecuária, a maior parte da população é urbana e com baixo nível de renda ${ }^{2}$. Devido à fraca dinâmica econômica, os estabelecimentos de comércio e serviços existentes são de pequeno porte e de caráter local, se localizando em alguns núcleos e

\footnotetext{
${ }^{2}$ Segundo dados do Censo IBGE 2000, 70\% da população do município é urbana, com a renda concentrada na faixa de 0 a 2 salários mínimos, sendo praticamente insignificante a faixa de renda de mais de 10 salários mínimos.
} 
em áreas lindeiras ao sistema viário principal e no entorno de algumas praças. De uma maneira geral, a população sofre com a falta de equipamentos urbanos, especialmente de cultura, lazer e educação.

Os impactos ambientais resultantes da ação antrópica estão principalmente associados à poluição das águas (superficiais e subterrâneas) e do solo: a disposição inadequada dos resíduos sólidos, o manejo inapropriado do cemitério, o uso de agroquímicos, a ocupação das margens dos cursos d'água, a contaminação das águas do Rio Bagagem pelas cidades que se localizam a montante e a falta de tratamento de esgoto. Em algumas áreas se verifica riscos de inundação, escorregamento e erosão. A produção agrícola e mineração (de pequena escala), por sua vez, são responsáveis também pela redução de cobertura vegetal natural (devido ao desmatamento) e pelo assoreamento do rio e a deposição inadequada de resíduos sólidos em bota-foras irregulares.

Os poucos equipamentos públicos existentes - escolas, hospital, a Câmara Municipal, a Prefeitura, creches, quadras poli-esportivas, praças, dentre outros - se concentram no Distrito Sede e em Santa Rita, o que dificulta o acesso dos mesmos à toda população. Dessa forma, os demais distritos se encontram numa posição desprivilegiada e pode-se dizer que vivem na condição de periferia, já que estão distantes e desconectados da estrutura urbana principal do município.

Há que se destacar, no entanto, que a estagnação econômica favoreceu a preservação do patrimônio edificado e das características rurais da paisagem, marcada pela presença do rio e das montanhas da região. Os distritos Sede e Santa Rita concentram o acervo arquitetônico e urbanístico mais significativo do município que se encontra, na sua maioria, em processo de degradação ou em total abandono por seus proprietários. Contudo, esses distritos preservam a morfologia básica de seu traçado oitocentista e poucos acréscimos foram feitos à malha original, apesar de que, algumas delas, ocorreram sem consideração à paisagem ambiental e funcionam como elementos de descaracterização da ambiência do lugar.

O Plano Diretor Participativo de Estrela do Sul buscou, portanto, apresentar possíveis caminhos de superação da problemática apresentada: os problemas ambientais; a estagnação econômica; a desarticulação social, econômica e cultural; a descontinuidade e fragmentação espacial; a falta e o acesso às infraestruturas. Para isso, partiu-se do princípio de que a cidade dispõe de recursos naturais e bens históricos que podem ser potencializados por meio de ações de incentivo e desenvolvimento do turismo ecológico e rural, e que pode dar a ela um protagonismo no roteiro de cidades históricas de Minas Gerais.

Nesta perspectiva, o Plano teve como diretrizes: a redefinição da área do perímetro urbano do Distrito Sede e Distrito de Santa Rita e a determinação dos perímetros urbanos dos demais distritos; a proposição de programas de formação profissional, direcionados às vocações de cada distrito e de diretrizes e ações para as questões culturais, paisagísticas, econômicas; a ordenação e o controle do uso e ocupação do solo urbano; a valorização dos espaços públicos como áreas destinadas à manifestação da vida coletiva; a criação de programas de preservação, recuperação e conservação do patrimônio natural e cultural; a implementação de programas habitacionais de interesse social; a recuperação dos laços (links) ecológicos rompidos pela ação antrópica para estabelecer novas possibilidades de reestruturação do ecossistema nativo e garantir a indução da sustentabilidade ambiental. 


\section{A formulação dos Cenários Ambientais para Estrela do Sul}

Para a geração das propostas de ação do Plano Diretor Participativo de Estrela do Sul foi utilizado a metodologia de criação de cenários futuros. De acordo com Franco (2000) , esse é um método de projeto que se aplica a qualquer mosaico paisagístico, com abordagem ligada à estrutura, função e mudança, e devem atender aos ideais de concentração, conexão e conservação, para, a partir daí, se pensar a melhor forma de se adequar ao uso do solo as condições ecossistêmicas. É, portanto, um método que parte de cenários ambientais existentes e busca soluções para uma determinada problemática por meio da projeção de uma situação futura. Dessa forma, a leitura ambiental prévia, detalhada, é de fundamental importância para a identificação dos cenários existentes, pois é a partir dela que se é possível problematizar a respeito das condições ambientais de um lugar.

A elaboração dos diversos cenários teve como princípio norteador o (re)ordenamento territorial sob a ótica da sustentabilidade, em sua perspectiva cultural e ambiental. Isso requereu, seguindo Zancheti (2000), a identificação: das áreas que necessitam de pequenas alterações no sentido de melhor se adequar às velhas e/ou novas funções; dos espaços transitórios que deverão passar por processos de transformação de vários dos seus elementos para melhor se adequarem aos usos propostos; dos espaços de grande valor ambiental, destinando-lhes uso adequado para preservá-los para as gerações futuras; das redes como estratégia de organização espacial e como principal meio de direcionar, com critérios de maior equidade social, os processos de provimento de infraestruturas e serviços urbanos.

Buscou-se desenvolver uma concepção de desenvolvimento ambiental e econômico equilibrado, com o intuito de reduzir as taxas de desigualdade social e de superar as dificuldades impostas pelo modelo econômico moderno, concentrador de poder e excludente. E, para a constituição de um projeto do desenvolvimento local, foram explorados ainda os conceitos de mobilidade e redes e de ecoturismo.

Com base na diversidade dos lugares urbanos e das unidades ambientais significantes do município, em termos de valores da natureza, cultura e história, a estrutura espacial proposta é constituída pelos elementos do ambiente natural - hidrografia, cobertura vegetal e solo -, e do ambiente construído - paisagem urbana, patrimônio histórico-cultural e formas de uso do solo.

A partir do diagnóstico elaborado, considerando as potencialidades e tendências do município, foi proposta uma divisão territorial e a identificação dos problemas urbanos a serem enfrentados a médio e longo prazo pelo município, bem como pelo direcionamento e desenvolvimento econômico sustentável pretendido para os diversos distritos, tendo como objetivos específicos: a regulação da ocupação do solo, controlando o adensamento em áreas sem infra-estrutura e equipamentos públicos ou comunitários; a qualificação, a indução e a restrição dos usos em cada área da cidade; a definição das áreas destinadas à criação de unidades de conservação e/ou parques urbanos; a preservação, a recuperação e a sustentação das áreas de interesse histórico e ambiental; a urbanização e a qualificação da infra-estrutura e a habitabilidade nas áreas de risco e ocupação precária. 
Assim, a divisão territorial foi feita a partir da idéia de paisagem como cenário, tratando cada cenário como "unidade de estudo, definidos tanto nas áreas de ambiente natural quanto de ambiente construído. A partir dos critérios de: significado histórico-cultural; potencial turístico; importância ambiental; uso e ocupação do solo; interesse social e desenvolvimento econômico do Município de Estrela do Sul, e buscando contemplar todos os níveis que caracterizam a dinâmica urbana, foram definidos os cenários de: Preservação, Recuperação e Conservação Ambiental; Identidade Cultural; Turismo; Adensamento Urbano; Inclusão Social; Mobilidade Urbana Sustentável e Desenvolvimento Econômico Sustentável, que resultaram no cenário síntese, HistóricoAmbiental.

Cabe destacar que a preocupação não foi de definir pontos específicos de intervenção, mas as áreas que deveriam ser objeto de ações para alcançar os diferentes objetivos.

O Cenário de Preservação, Recuperação e Conservação Ambiental é formado pelos elementos de hidrografia e de vegetação, tanto as Áreas de Preservação Permanente APP's, como também as áreas verdes existentes no tecido urbano.

A rede hídrica do município foi tratada como elemento estruturador do território e é formada pelo Rio Bagagem, córregos e cursos d'água dentro e fora da malha urbana, integrantes da Bacia do Rio Paranaíba.

A vegetação do município é constituída por elementos de: Cerrado (o ecossistema característico do Triângulo Mineiro), Veredas e Floresta Estacional Semidecidual, e também pela arborização urbana.

O Cerrado, durante muito tempo, foi considerado terra de pouca fertilidade, apropriada apenas para algumas culturas agrícolas e a criação de gado. No entanto, atualmente se reconhece a importância desse ecossistema como depositário de grande diversidade de fauna e flora, sendo que no seu interior encontra-se uma variedade significativa de comunidades e formas de vegetação de estruturas diferentes do Cerrado típico, com a presença de campos, Matas Ciliares ou Galerias às margens dos cursos d'água é também de Veredas.

As Veredas são uma formação campestre localizada em vales suaves, com surgência do lençol freático na superfície do solo, sem demarcação de uma drenagem definida. É dominada por elementos vegetais graminosos, e destacada pela presença do buriti (uma palmeira arbórea, de ocorrência exclusiva nessas formações). Por estarem ligadas às nascentes de pequenos corpos d'água, são incluídas nas Áreas de Preservação Permanente (APP), definidas por legislação federal.

Ao contrário das Veredas, a Floresta Estacional Semidecidual são formações florestais exuberantes, com árvores de até $30 \mathrm{~m}$ de altura, localizadas nas encostas e nos fundos dos vales. $\mathrm{Na}$ escala do mapeamento realizado, essas formações incluem, além da floresta estacional semidecidual propriamente dita, também as áreas de floresta estacional decidual (que ocorrem sobre afloramentos rochosos) e as matas ciliares e de galeria, que margeiam os corpos d'água de diferentes dimensões.

Esses espaços livres foram concebidos como uma infra-estrutura verde, decisivos na estratégia de reverter a degradação ambiental e recuperar a paisagem para que a cidade 
possa abrigar um turismo histórico e rural, capaz de criar uma nova base econômica e garantir novas perspectivas de vida para seus habitantes.

O termo infra-estrutura verde aqui é usado segundo a definição de Pellegrino et al. (2006, p. 60) e se refere a um sistema de espaços livres que desempenham funções que vão muito além das visões eminentemente estéticas ou funcionalistas comumente a eles relacionados, ou seja, de circulação, contemplação e recreação. Refere-se, portanto, às novas abordagens que visam conciliar a manutenção de fragmentos de vegetação ou de ecossistemas naturais e a ocupação humana, garantindo a sustentabilidade urbana e a manutenção da biodiversidade nas cidades.

As áreas que compõem esse Cenário são, portanto, as localizadas nas: marginais ao longo do Rio Bagagem, córregos, lagos ou reservatórios de água naturais ou artificiais e nascentes, ainda que intermitentes; nos morros, regiões escarpadas, chapadas e nos parques propostos. Elas foram tratadas com fim de exercerem a função de conservar os recursos hídricos, a paisagem, a estabilidade geológica, a biodiversidade, o fluxo gênico da fauna e flora, proteger o solo e assegurar o bem-estar das populações humanas, além de funcionarem como instrumentos de interesse sócio-cultural e de indução a sustentabilidade ambiental.

O Cenário de Preservação, Recuperação e Conservação Ambiental estrutura-se em três faixas consecutivas:

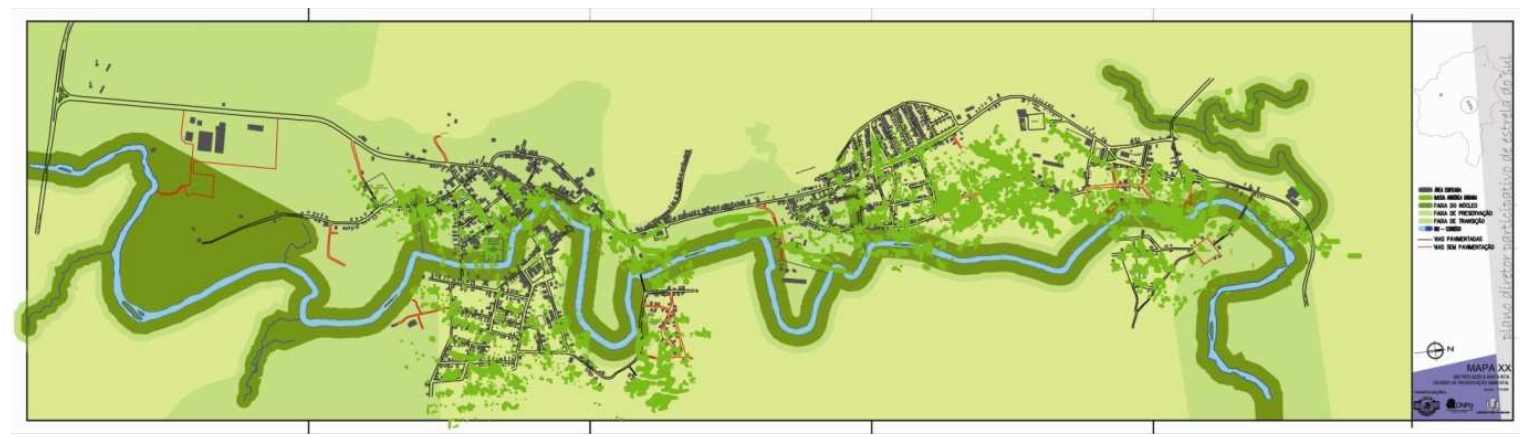

Figura n01 - Cenário de Preservação, Recuperação e Conservação Ambiental

I - Núcleo: faixas de, no mínimo, 80 metros de largura nas margens do Rio Bagagem e de, no mínimo, 50 metros de largura nas margens dos córregos e nascentes. Com a função de conservar o meio ambiente existente, nessa área, a natureza deverá permanecer intacta, não se tolerando quaisquer alterações humanas, representando o mais alto grau de preservação.

O objetivo dessa faixa é, portanto, a recuperação das áreas de fundo de vale, o controle das erosões e a recuperação da mata ciliar através do plantio de espécies nativas, a despoluição dos recursos hídricos ou através da regeneração natural. Considera-se essa faixa essencial, tanto para a sobrevivência de espécies da fauna, flora e biota regionais consideradas vulneráveis, endêmicas ou ameaçadas de extinção, bem como para biótopos raros de significados regionais e nacionais.

São permitidas atividades submetidas ao uso controlado e limitado a preservação/conservação, pesquisa científica, ecoturismo, a implantação de parques 
lineares, a manutenção dos remanescentes florísticos e a garimpagem de subsistência (no curso do Rio Bagagem);

II - Preservação: faixas contíguas ao Núcleo de, no mínimo, 50 metros, para proteção dos ecossistemas, dos recursos genéticos e monitoramento ambiental, que promovem a conexão do meio natural e do meio urbano de modo controlado, com o mínimo impacto humano.

O objetivo dessas áreas é promover a proteção do Núcleo, a recuperação do meio ambiente existente e a requalificação das áreas urbanas consolidadas, por meio da adequação dos espaços com a elaboração de normas específicas de uso e ocupação a serem definidas no Plano Municipal de Preservação Ambiental.

Nestas faixas é permitida a instalação de equipamentos que favoreçam o uso recreativo, educacional e de lazer, implantados de forma controlada, privilegiando o adensamento da cobertura vegetal, a permeabilidade do solo e o controle dos recursos hídricos.

III - Transição: áreas de manutenção do meio ambiente, que promovem a passagem entre os meios naturais e urbanos.

Com o propósito de minimizar os impactos negativos provocados pela infra-estrutura e adensamento urbano, o uso dessas áreas deverá ser regulamentado por normas e restrições específicas para as atividades humanas no tecido urbano existente, como o controle do uso e as taxas de ocupação do solo, a normatização no plantio da vegetação, o controle de poluentes, o tratamento de efluentes, o tratamento, disposição e reciclagem de resíduos, a redução do consumo de energia e água, o monitoramento da água pluvial, entre outros.

O Cenário de Identidade Cultural é composto pelas áreas de Conservação e de Transformação existentes, tanto do meio ambiente natural quanto do ambiente construído.

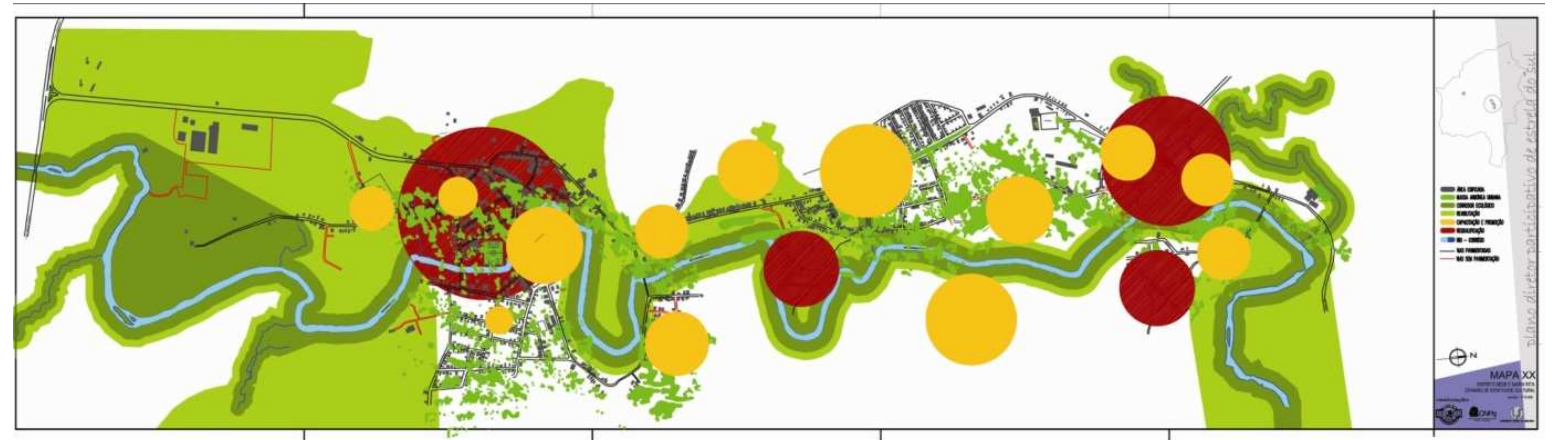

Figura n0ㅜ - Cenário de Identidade Cultural

A definição das mesmas partiu dos princípios que nortearam as diretrizes para a conservação patrimonial estabelecidas na $2^{\mathrm{a}}$ Conferência Mundial do Meio Ambiente ECO 92, realizada no Rio de Janeiro, que relaciona a conservação patrimonial aos princípios sociais e às políticas de conservação ambiental, e que defende a necessidade de qualificação e requalificação das estruturas urbanas estabelecidas. Seguindo estes princípios, as estruturas urbanas devem ser utilizadas, maximizadas e/ou transformadas, 
de um modo sustentável, para a satisfação das necessidades atuais, garantindo a manutenção da riqueza ambiental urbana existente (ZANCHETTI, 2000). Dessa forma, as intervenções urbanas devem garantir a formação de uma imagem urbana em que se valorizam as especificidades da cultura local, manifestada por meio dos recursos patrimoniais, destacando-se os que apresentam valor de antiguidade.

A paisagem urbana se estrutura por elementos do meio físico natural e construído, resultado da ação humana e cultura local cujas características configuram sua história, sendo aspecto essencial da identidade cultural do município. Em Estrela do Sul, essa paisagem é marcada por um conjunto arquitetônico e urbanístico significativo, típico de cidades históricas do século XVIII, com formação urbana representativa dos arraiais de mineração.

O ambiente construído foi tratado com o objetivo de promover a distribuição espacial equilibrada dos usos e atividades urbanas, como meio de garantir os múltiplos usos em todos os distritos e possibilitar o maior acesso à população. Através da criação de novas centralidades, com o estímulo das atividades econômicas de comércio e serviço adequadas à infra-estrutura existente, espera-se contribuir para o desenvolvimento de cada local e, conseqüentemente, reduzir os deslocamentos. Espera-se, ainda, regular as atividades incômodas e/ou prejudiciais e implantar empreendimentos de impacto socioeconômico e urbanístico.

Com base nesses pressupostos, para o Município de Estrela do Sul foram definidas:

a) Áreas de Conservação: as áreas do tecido urbano que já possuem uma certa uniformidade das tipologias de edificação e um traçado urbano consolidado, que necessitem, porém, de ações de reparação, melhoria e conservação. Elas compreendem as áreas/regiões onde estão os bens materiais e imateriais de interesse histórico-cultural.

Para essas áreas, as diretrizes de ação compreendem: o levantamento, a identificação e o inventário dos bens culturais (materiais ou imateriais); a requalificação ou o restauro dos bens materiais móveis e imóveis, em sua maioria em estado de degradação; a requalificação do entorno, dando-se prioridade inicial aos bens tombados.

b) Áreas de Transformação: as novas áreas de interesse histórico-cultural existentes no tecido urbano ou nas áreas de expansão, que podem, inclusive, serem implantadas em áreas/edificações requalificadas e restauradas.

Elas compreendem as: (a) Áreas de Reabilitação, propícias à criação de novas áreas de interesse histórico-cultural, como bibliotecas, cinemas, igrejas, praças, centros comunitários, museus, centros culturais etc., prioritariamente dentro do tecido urbano consolidado; (b) Áreas de Capacitação e Promoção: criação de centros de capacitação de mão-de-obra, como oficinas, centros comunitários, escolas de restauro, cursos profissionalizantes, cooperativas etc. Elas visam desenvolver trabalhos de requalificação nas áreas de interesse histórico-cultural, e promover a divulgação e o resgate da identidade cultural local.

Dessa forma, o que se buscou foi a formação de um cenário final que promovesse a valorização da identidade cultural, com ações diferenciadas para cada ponto do território. Nos diversos distritos foram definidos os diversos núcleos de intervenção, de acordo com suas características: núcleos de requalificação (locais onde concentram maior acervo de 
bens culturais imóveis), núcleos de capacitação e promoção e núcleos de conexão para fomentar o surgimento ou reforço de um pequeno centro em cada distrito, com a implantação prioritária de equipamentos públicos. Assim, a partir do tratamento de algumas áreas promover uma "costura" nos núcleos existentes e propostos, já que uma das principais características do tecido urbano é a descontinuidade espacial existente.

No Cenário de Turismo foram indicadas as áreas de elevado valor histórico-cultural e/ou ecológico, com o objetivo de promover a valorização da cultura e história locais, a experiência educacional interpretativa e o conhecimento do meio ambiente natural, visando um desenvolvimento econômico sustentável, por meio da utilização dos recursos naturais, sem comprometer a sua capacidade de renovação e conservação.

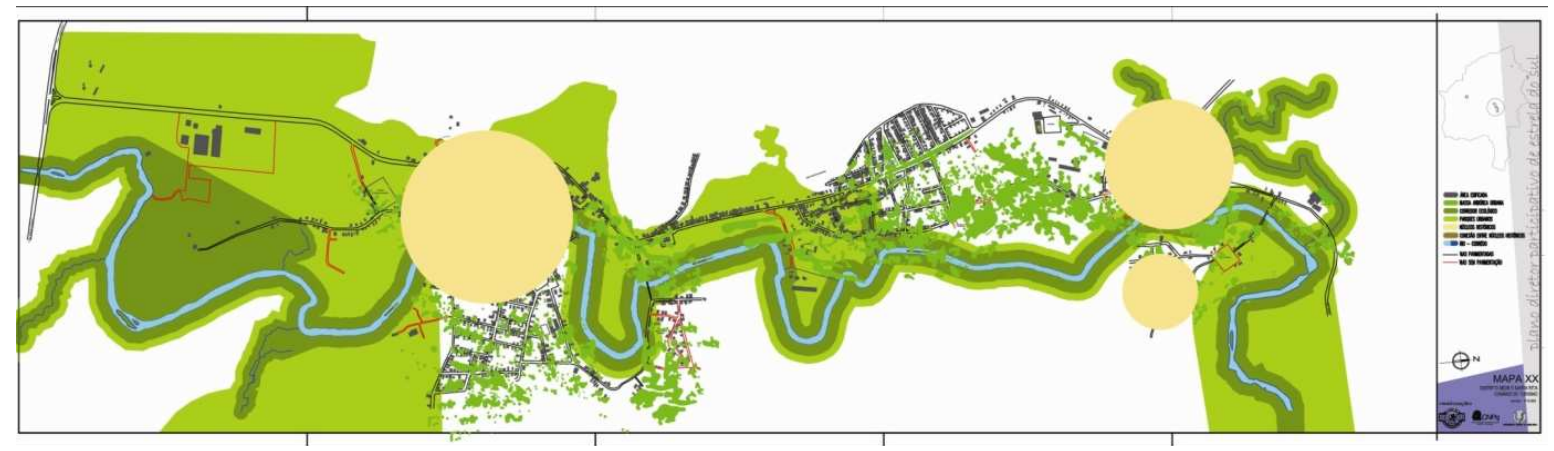

Figura no03 - Cenário de Turismo

Essas áreas dividem-se em: áreas urbanas e rurais de interesse histórico-cultural, áreas de conservação do patrimônio natural e as áreas preservação ambiental. Elas deverão receber infra-estrutura adequada e disponibilidade de recursos humanos capacitados, além de um controle eficaz por meio da regulamentação do número de visitantes e de fluxo de transportes, a fim de reduzir ao máximo os impactos negativos causados pela prática do turismo.

Para as áreas de interesse histórico-cultural estão previstas ações de requalificação/restauração/recuperação com o fim de promover o resgate histórico-cultural local, podendo receber atividades complementares a atividade de turismo, como lojas, centros culturais, museus, restaurantes, hotéis e pousadas, associados a atividades como cavalgadas, caminhadas em trilhas, esportes radicais, entre outros.

As ações para as áreas de conservação do patrimônio natural visam promover a conservação da biodiversidade por meio de remanescentes florestais, possibilitando o livre trânsito de animais e a dispersão de sementes das espécies vegetais, e podem receber atividades ligadas à contemplação e apreciação da paisagem e ao uso com atividades restritas e controladas.

As áreas preservação ambiental são áreas rurais cedidas por proprietários por livre iniciativa, a fim de elaborar uma rede particular de Unidades de Conservação do patrimônio natural, devendo receber incentivos de ITR - Imposto Territorial Rural, concedido pelo IBAMA.

No Cenário de Adensamento Urbano foram designadas as áreas de transformação e passíveis de urbanização, sobretudo aquelas que apresentam vazios ou descontinuidades 
no tecido urbano, em que se deve complementar parte do ambiente construído, observados os critérios de mitigação dos impactos ambientais e a implantação de infraestrutura urbana e de equipamentos adequados.

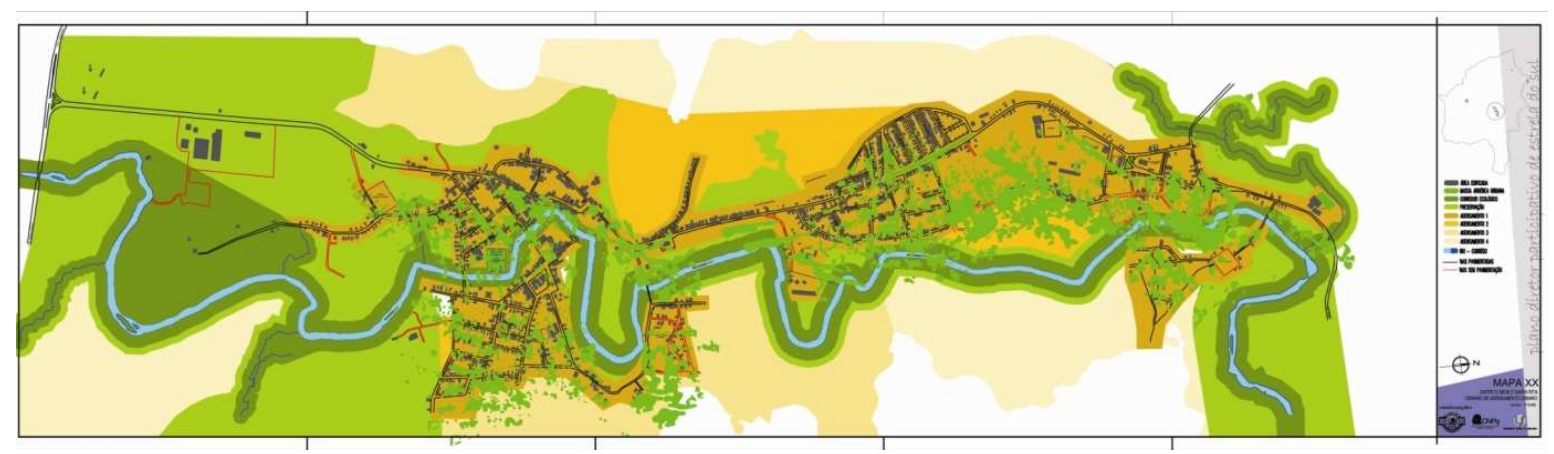

Figura noㄴ - Cenário de Adensamento Urbano

Abrange diversas áreas com diferentes graus e diretrizes para o seu adensamento. Ao redor das áreas urbanizadas já existentes, considerada como áreas de ocupação prioritária, foram definidas as demais, que formam uma espécie de anéis ao redor da primeira, ou seja, são as áreas lindeiras ao tecido urbano consolidado, que ainda não estão parceladas, mas que, conforme a demanda, deverão ser ocupadas gradativamente e somente após a ocupação das áreas que formam os anéis anteriores, devendo receber infra-estrutura adequada e equipamentos urbanos.

Dessa forma, esse Cenário prevê ações imediatas para as áreas urbanizáveis localizadas dentro do tecido urbano existente. A finalidade é promover a ocupação dos vazios e a "costura" da malha por meio da urbanização qualificada dessas descontinuidades, visando enfraquecer os mecanismos de especulação imobiliária.

Essas áreas destinam-se a usos que visam mitigar os impactos ambientais onde, por meio de legislação específica, devem ser criados incentivos fiscais para a instalação de equipamentos relacionados ao desenvolvimento do turismo local, como hotéis, pousadas, restaurantes, entre outros, estimulando o ordenamento do uso e ocupação do solo, bem como assegurada a reserva de áreas verdes e para uso institucional nos novos loteamentos ou parcelamentos.

O Cenário de Inclusão Social consiste nas áreas do território municipal que requerem tratamento específico e destinam-se primordialmente à produção, manutenção e recuperação de áreas, edificações ou meios que promovam a inclusão social, como equipamentos de infra-estrutura básica (moradia, saúde, educação, lazer, segurança, assistência social etc.) e complementar (cooperativas, centros de capacitação, centros comunitários, centros de convivência, centros de inclusão digital, bibliotecas etc.), que devem estar localizados nas áreas centrais do tecido urbano ou onde haja demanda, com fácil acesso para todos os cidadãos. 


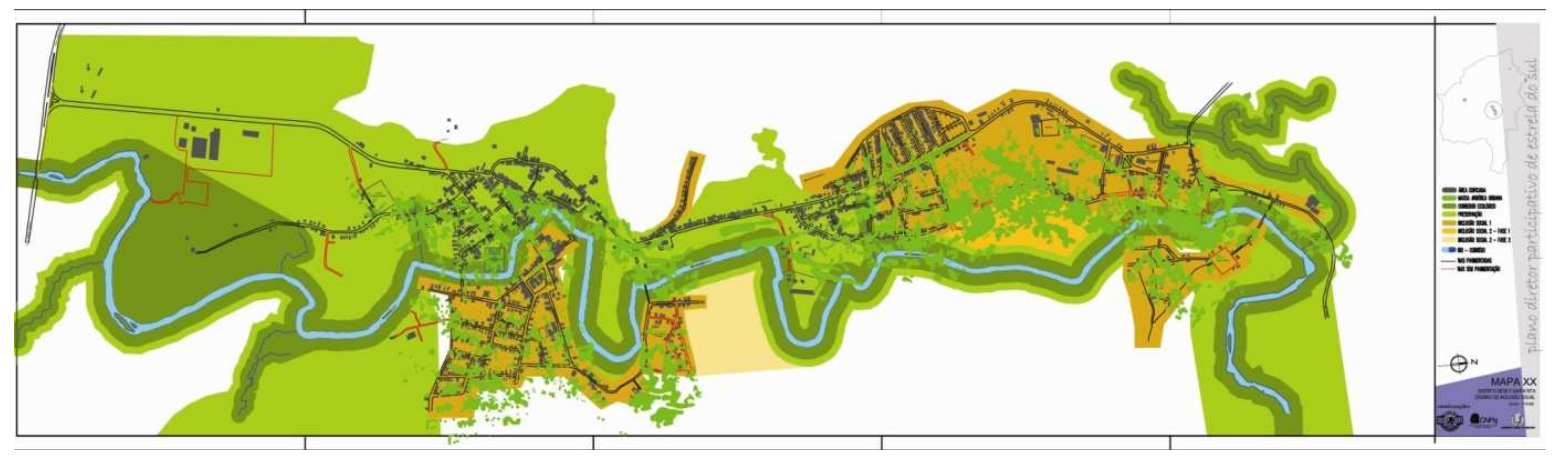

Figura nํ5 - Cenário de Inclusão Social

O cenário é formado pelas áreas, edificações ou terrenos não edificados, subutilizados ou não utilizados, incluindo-se as áreas requalificadas, destinadas a receber a instalação desses equipamentos e integrar as áreas do tecido urbano. A distribuição e implantação dessas áreas obedecem a mesma lógica do Cenário Adensamento Urbano: deverão ser dada prioridade às áreas já ocupadas e as novas deverão ser criadas apenas após a ocupação e o adensamento das mesmas.

Além disso, este Cenário prevê a criação de Áreas de Habitação de Interesse Social, localizadas dentro do tecido urbano consolidado, com fácil acesso e que, conforme haja demanda, devem receber incentivos e subsídios para implantação de loteamentos para população de baixa renda, facilitando o acesso à moradia a todos os cidadãos.

O Cenário de Mobilidade Urbana Sustentável consiste em áreas do território que, por meio de ações sobre a gestão do sistema viário e dos transportes, integrada com a política de desenvolvimento urbano, visam proporcionar acesso aos bens e serviços de uma forma eficiente para todos os habitantes, priorizando os modos de transporte coletivo e os não-motorizados, de forma segura, socialmente inclusiva e sustentável.

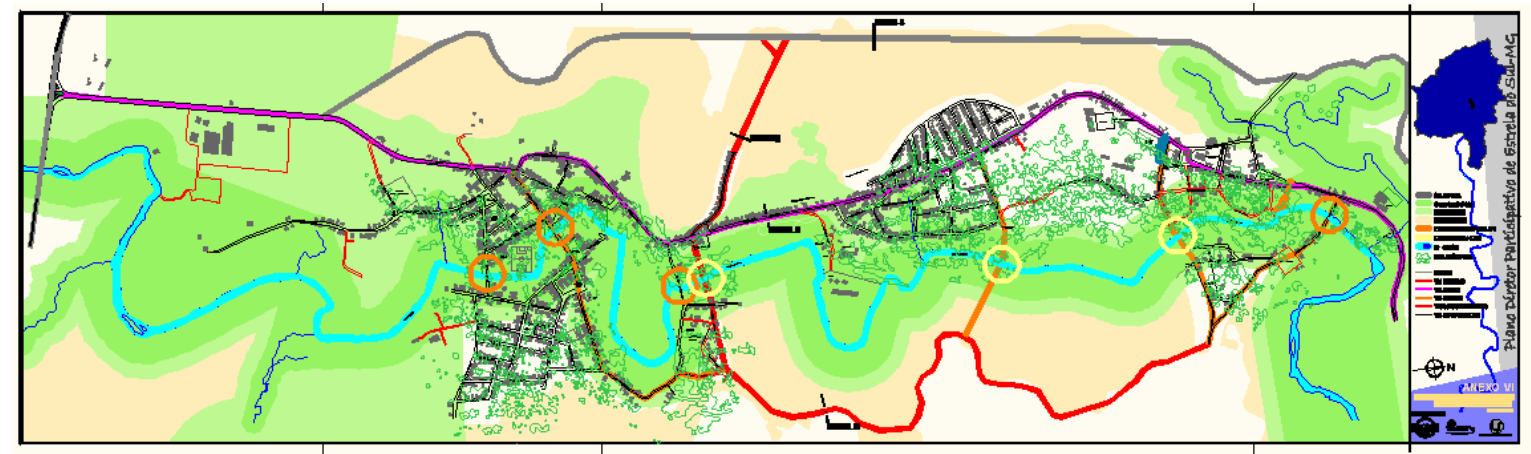

Figura nํ0 - Cenário de Mobilidade Urbana Sustentável

Abrange: as vias existentes, que deverão receber reparos, sinalização e controle do tráfego; as vias reformuladas, que, além das medidas anteriores, necessitam também de adequação das caixas de rolamentos; as vias novas, a serem criadas; as vias históricas, que deverão ser recuperadas as pavimentações originais (pedras) e adotadas o sistema binário de circulação, com fim de adequá-las ao tráfego e diminuir o impacto causado pelos veículos nessas vias; as ciclovias, localizados nas bordas das principais vias de 
tráfego e com desenho adequado para receber formas de circulação não-motorizadas; os passeios, que deverão ser re-dimensionados e receber tratamentos adequados por meio de intervenções viárias e paisagísticas, a alocação de mobiliário urbano, travessias seguras e outros elementos que facilitem a circulação e o bem estar do pedestre, a implantação de pisos adequados antiderrapantes bem como o acesso desimpedido e a utilização de sinalizações adequadas às pessoas portadoras de deficiência de locomoção.

Esse Cenário inclui também ações em relação aos transportes, concebido a partir de um sistema de transporte público coletivo regular entre o Distrito Sede e os demais, garantindo o atendimento adequado aos usuários em termos de demanda, itinerários e freqüência dos ônibus. Prevê também a criação de um itinerário turístico de forma a promover o acesso às áreas de interesse histórico e turístico, auxiliando o deslocamento e o acesso aos diversos pontos de interesse turístico do município. As diretrizes indicam, também, a necessidade de regulamentação de uma tarifa socialmente justa, que garanta a mobilidade e acessibilidade principalmente à população carente.

O Cenário de Desenvolvimento Econômico Sustentável é formado pelas áreas do território que, por meio da conciliação entre o crescimento econômico e a preservação ambiental, produzam a riqueza material no Município, assim como o bem-estar econômico de seus habitantes.

Essas áreas deverão sofrer ajustes institucionais, fiscais e jurídicos por meio de incentivos, inovações e investimentos, no intuito de fornecer condições para um sistema eficiente de produção e distribuição de bens e serviços à população, dividindo-se em:

I - Núcleos de Convivência e Integração Atuais e Futuros: são as áreas identificadas dentro do tecido urbano, principalmente em torno das principais praças, com predominância de usos comerciais e de serviços, que devem ser fortalecidos através de incentivos fiscais, distribuindo atividades diferenciadas por toda malha urbana, com o intuito de promover a integração no tecido urbano e a sociabilização entre os diversos setores da cidade;

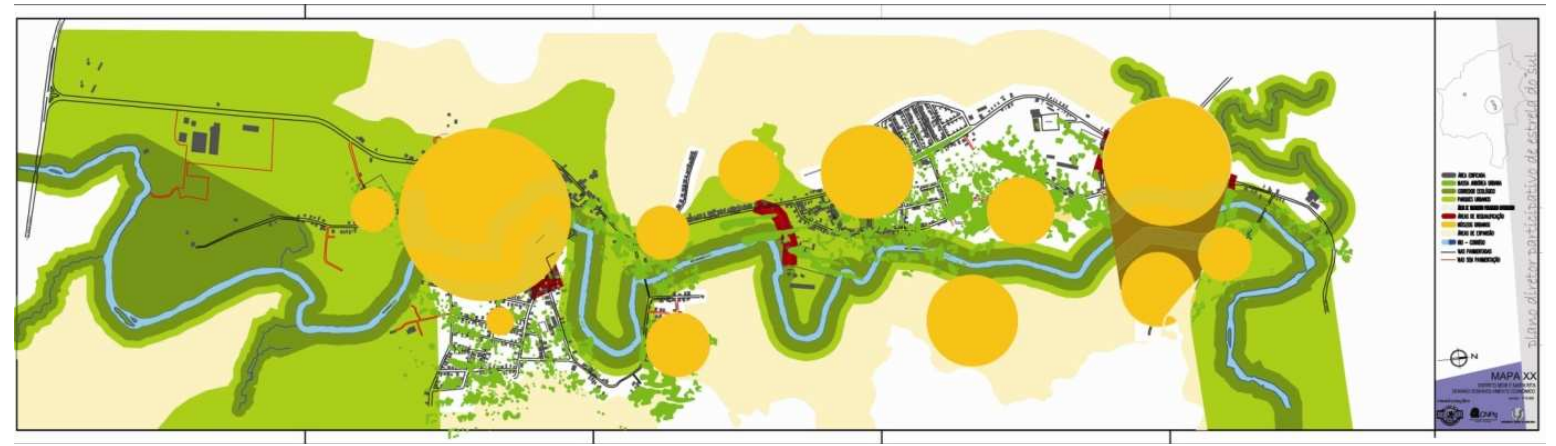

Figura n07 - Cenário de Desenvolvimento Econômico Sustentável

II - Núcleos Históricos e Culturais: são áreas passíveis de restauração e/ou requalificação, que podem receber atividades diferenciadas, especialmente as que dão suporte as atividades turísticas;

III - Corredor Comercial: são os eixos comerciais e de serviços nas áreas indicadas que deverão ser fortalecidos para promover a unicidade do tecido urbano, no intuito de viabilizar os fluxos de circulação e articular as diferentes atividades; 
IV - Corredor de Ecoturismo: são áreas de preservação ambiental permanente ao longo dos cursos d'água, por meio da implantação de parques urbanos e lineares com equipamentos recreativos, de lazer, educacionais e de apoio, que visem à promoção de atividades ecoturísticas, monitoradas e controladas, por profissionais capacitados;

V - Áreas de Expansão: são áreas urbanizáveis, inseridas dentro do tecido urbano, constituídas por lotes vagos e vazios urbanos, que já apresentam infra-estrutura, que devem, quando necessário, receber novo traçado, fazendo-se a "costura" da malha por meio da urbanização qualificada dessas lacunas e enfraquecendo os mecanismos de especulação imobiliária.

Todos esses Cenários resultam no Cenário Síntese ou Cenário Histórico-Ambiental que reflete todas as ações articuladas entre si, visando a conciliação entre o crescimento econômico e a preservação histórico-ambiental. Pensa-se que, desse modo, as ações funcionam como instrumentos de interesse sócio-cultural, de indução a sustentabilidade ambiental e de inclusão social.

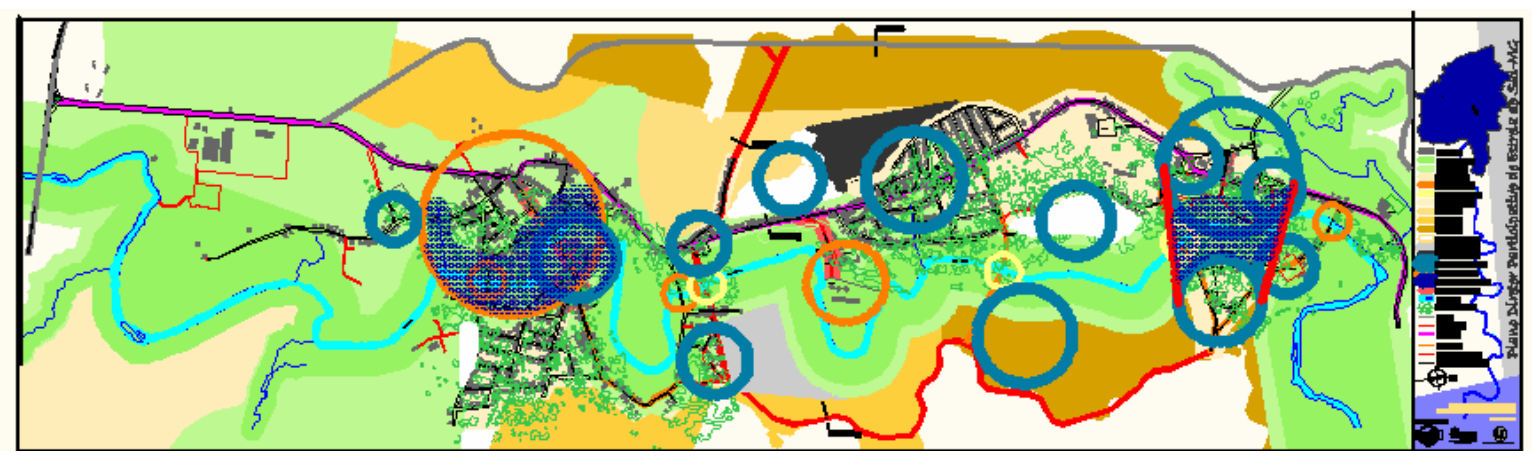

Figura n0ㅇ - Cenário Histórico-Ambiental

\section{Considerações}

Do que foi exposto, podemos constatar que o Plano Diretor Participativo de Estrela do Sul buscou promover uma ação integrada sobre todo o território, por meio da articulação dos diversos espaços existentes e dos problemas apresentados.

O ponto de partida para as ações foi uma cuidadosa leitura técnica e comunitária, que resultou na elaboração dos Cenários, uma espécie de layers que contêm as proposições para os problemas apresentados, em suas diversas dimensões. Buscou-se, portanto, apresentar caminhos para a superação dos problemas ambientais, econômicos, a desarticulação social e cultural, a descontinuidade e fragmentação espacial, e a falta e o acesso às infraestruturas por meio da valorização e da articulação dos ambientes naturais e urbanos.

Os princípios de conservação, preservação e recuperação do patrimônio cultural e sustentabilidade ambiental nortearam a elaboração das propostas, que emergiram, sobretudo, a partir da leitura e do reconhecimento do valor dos elementos naturais e construídos. Dessa forma, os cenários de Preservação, Recuperação e Conservação Ambiental e o de Identidade Cultural foram as bases da proposta, a partir do qual os demais foram sendo elaborados com o propósito de definir as áreas que, em seu conjunto, deveriam qualificar e dar coesão à todo o território. 
A forma como os espaços livres (urbanos ou naturais) foram tratados, baseia-se nos conceitos paisagísticos e ecológicos e podem, portanto, ser entendidos como uma infraestrutura verde, na medida em que buscam integrar os conjuntos dos espaços edificados e não edificados num único sistema, que permeia todas as escalas. As áreas verdes, especialmente nas áreas urbanas, foram definidas na forma de faixas concêntricas, ao redor dos cursos d'água ou núcleos significativos de vegetação natural, cujo objetivo é manter o núcleo intacto, ao mesmo tempo em que se permite a introdução gradual e controlada de elementos vegetais e equipamentos de uso comunitário. No conjunto, essas diferentes áreas estarão conectadas e funcionando como um todo, visando a recuperação e integração dos espaços ainda naturais com os já urbanizados.

Dessa forma, entende-se que a requalificação e revalorização dos espaços urbanos e naturais do Município de Estrela do Sul será a chave para o estabelecimento de novas bases para o seu desenvolvimento, permitindo a exploração do potencial turístico da cidade e região, de forma a garantir a qualidade de vida de seus habitantes e promover o desenvolvimento sustentável da região.

\section{Referências}

ARANTES, Otília B. F. Uma estratégia fatal. A cultura das novas gestões urbanas. In ARANTES, Otília. B. F., VAINER, Carlos, MARICATO, Ermínia. A cidade do pensamento único. Desmanchando consensos. Petrópolis, RJ: Vozes, 2000.

BRASIL. Ministério das Cidades. Plano Diretor Participativo. Guia para a elaboração pelos municípios e cidadãos, 2004.CHOAY, Françoise. A alegoria do patrimônio. São Paulo: Estação Liberdade: Ed. da UNESP, 2006.

FRANCO, Maria de Assunção R. Planejamento Ambiental para a cidade sustentável. São Paulo: Annablume \& Furb \& FAPESP, 2000.

LEFF, Henrique. Saber Ambiental: Sustentabilidade, Racionalidade, Complexidade, Poder. Petrópolis: Vozes, 2001.

PELLEGRINO, Paulo Renato Mesquita, GUEDES, Paula Pinto, PIRILLO, Fernanda Cunha, FERNANDES, Sávio Almeida. A paisagem da borda: uma estratégia para a condução das águas, da biodiversidade e das pessoas. In COSTA, Lúcia Maria Sá (org.). Rios e paisagens urbanas em cidades brasileiras. Rio de Janeiro: Viana \& Mosley: Ed. PROURB, 2006, p. 57-76.

SÃO PAULO. Prefeitura do Município de São Paulo - PMSP / Programa das Nações Unidas para o Meio Ambiente - PNUMA. Panorama do Meio Ambiente Urbano GEO CIDADES de São Paulo 2004. Secretaria do Verde e do Meio Ambiente - SVMA da PMSP e Instituto de Pesquisas Tecnológicas do Estado de São Paulo - IPT, São Paulo, 2004.

VITAL, Giovanna Teixeira Damis. Desenho Ambiental em Uberlândia: o caso do Córrego Lagoinha. São Paulo. Dissertação (Mestrado) - Faculdade de Arquitetura e Urbanismo, Universidade de São Paulo, São Paulo, 2003. ZANCHETI, Silvio. Novas estratégias de conservação e gestão urbana. 2004. 